found resistance to trimethoprim in $20 \%$ of isolates from urinary infections in outpatients and in $40 \%$ from inpatientsfigures which contrast dramatically with a rate of less than $1 \%$ in Helsinki between 1972 and 1977, possibly because since its release in Finland in 1973 trimethoprim has not been as widely used. ${ }^{24}$

Though plasmid-mediated resistance seems to be much less common than chromosomal resistance, ${ }^{10} 13$ and accounted for only $10 \%$ of resistant strains in the Turku study, ${ }^{23}$ some authors have commented recently on a disturbing increase in the proportion of resistant organisms carrying trimethoprimresistance plasmids. ${ }^{1517}$ Plasmids conferring resistance to trimethoprim and sulphonamides were first recognised in 1971. ${ }^{25}$ At present, their natural frequency in Britain appears to be low, 1126 but the potential for dissemination of trimethoprim resistance in response to use of the drug is a possible threat to the continued success of treatment with trimethoprim alone. Plasmids differ in their ability to disseminate, but under suitable conditions they may give rise to epidemics of resistance. An outbreak of plasmid-borne trimethoprim resistance in London has been associated with heavy use of co-trimoxazole, sulphonamides, and ampicillin but was controlled by isolation of the patients and restriction of antibiotic use. ${ }^{27}$ Plasmid-encoded trimethoprim resistance in epidemic strains of bovine Salmonella typhimurium has provided further evidence that we need strict regulations to control the use of antibiotics in farming. ${ }^{28}$

The increasingly high proportion of strains being found with high-level, non-transferable resistance implies that genes for trimethoprim resistance may be transposed from plasmid to bacterial chromosome ${ }^{15}$ - a disturbing possibility, since resistance of this kind is stable and (unlike plasmid-mediated resistance) not likely to be lost when selective pressures from antibiotics are removed.

Clearly, trends in susceptibility to trimethoprim need to be monitored carefully. Diagnostic laboratories reporting antimicrobial sensitivities should test both sulphonamide and trimethoprim, not only co-trimoxazole, and should be aware of possible sources of error-in particular, heavy inocula which may suggest spurious resistance on disc testing, a notorious problem with folate antagonists. The resistance of organisms showing reduced zones in such tests should be confirmed by determinations of minimum inhibitory concentrations. ${ }^{13}$

The effectiveness and lack of toxicity of trimethoprim are useful properties for a urinary antimicrobial, particularly where long-term prophylaxis is required. It may yet find wider applications, perhaps in treating respiratory infections or enteric fever. Since antibiotic pressures may dispose to acquisition of trimethoprim resistance further appraisal may suggest that the drug's usefulness may best be preserved by using it primarily for treatment of infections in the community and controlling its use in hospitals.

${ }^{1}$ Bushby SRM. Combined antibacterial action in vitro of trimethoprim and sulphonamides. The in vitro nature of synergy. Postgrad Med $\mathcal{F} 1969$; 45, suppl: 10-8.

2 Grüneberg RN. The microbial rationale for the combination of sulphonamides with trimethoprim. I Antimicrob Chemother 1979;5,suppl B: 27-36.

${ }^{3}$ Brumfitt W, Hamilton-Miller JMT. Trimethoprim. Br f Hosp Med 1980 March:281-8.

4 Greenwood D. Relevance of in vitro synergy to therapy: does synergy between diaminopyrimidines and sulphonamides operate at concentrations achievable in urine? $\mathcal{f}$ Antimicrob Chemother 1979;5,suppl B: 85-9.

5 Stokes A, Lacey RW. Effect of thymidine on activity of trimethoprim and sulphamethoxazole. $\mathcal{F}$ Clin Pathol 1978;31:165-71.

- Anderson JD, Lacey RW, Lewis EL, Sellin MA. Failure to demonstrate an advantage in combining sulphamethoxazole with trimethoprim in an experimental. model of urinary infection. $\mathcal{f}$ Clin Pathol 1974;27:619-22.
7 Brumfitt W, Pursell R. Double-blind trial to compare ampicillin, cephalexin, co-trimoxazole, and trimethoprim in treatment of urinary infection. $\mathrm{Br}$ Med $\mathcal{F} 1972$;ii :673-6.

${ }^{8}$ Koch UJ, Schumann KP, Küchler R, Kewitz H. Efficacy of trimethoprim, sulfamethoxazole and the combination of both in acute urinary tract infections. Clinical and pharmacokinetical studies. Chemotherapy 1973; 19:314-22.

${ }^{9}$ Busk HE, Korner B. Trimethoprim resistance in Finland. Br Med $\mathcal{f} 1980$; 280:1054-5.

${ }^{10}$ Brumfitt W, Hamilton-Miller JMT, Grey D. Trimethoprim-resistant coliforms. Lancet 1977; ii :926.

11 Towner KJ, Pearson NJ, Cattell WR, O'Grady F. Chromosomal resistance to trimethoprim. Lancet 1978 ; i:1371.

12 Maskell R, Okubadejo OA, Payne RH, Pead L. Human infections with thymine-requiring bacteria. $\mathcal{F}$ Med Microbiol 1978;11:33-45.

${ }^{13}$ Hamilton-Miller JMT. Mechanisms and distribution of bacterial resistance to diaminopyrimidines and sulphonamides. $\mathcal{F}$ Antimicrob Chemother 1979 ; suppl B:61-73.

14 Lacey RW, Bruten DM, Gillespie WA, Lewis EL. Trimethoprimresistant coliforms. Lancet $1972 ; \mathrm{i}: 409-10$.

15 Towner KJ, Pearson NJ, Pinn PA, O'Grady F. Increasing importance of plasmid-mediated trimethoprim resistance in enterobacteria: two sixmonth clinical surveys. Br Med $\mathcal{F} 1980 ; 280: 517-9$.

${ }^{16}$ Grey D, Hamilton-Miller JMT, Brumfitt W. Incidence and mechanisms of resistance to trimethoprim in clinically isolated Gram-negative bacteria. Chemotherapy $1979 ; 25: 147-56$

17 Amyes SGB, Emmerson AM, Smith JT. R-factor mediated trimethoprim resistance; result of two three-month clinical surveys. $\mathcal{F}$ Clin Pathol $1978 ; 31: 850-4$.

18 Pearson NJ, Towner KJ, McSherry AM, Cattell WR, O'Grady F Emergence of trimethoprim-resistant enterobacteria in patients receiving long-term co-trimoxazole for the control of intractable urinary-tract infection. Lancet 1979 ;ii:1205-8.

19 Grüneberg RN. The use of co-trimoxazole in sulphonamide-resistant Escherichia coli urinary tract infection. F Antimicrob Chemother 1975;1: 305-10.

${ }^{20}$ Darrell JH, Garrod LP, Waterworth PM. Trimethoprim: laboratory and clinical studies. $\mathcal{F}$ Clin Pathol 1968;21:202-9.

21 Grüneberg RN, Leakey A, Bendall MJ, Smellie JM. Bowel flora in urinary tract infection: effect of chemotherapy with special reference to co-trimoxazole. Kidney Int $1975 ; 8$, suppl S:122-9.

22 Toivanen A, Kasanen A, Sundquist H, Toivanen P. Effect of trimethoprim on the occurrence of drug-resistant coliform bacteria in the faecal flora. Chemotherapy 1976;22:97-103.

${ }^{23}$ Huovinen $\mathrm{P}$, Toivanen $\mathrm{P}$. Trimethoprim resistance in Finland after five years' use of plain trimethoprim. $B r M e d \mathcal{F} 1980 ; 280: 72-4$.

${ }^{24}$ Kasanen A, Anttila M, Elfving R, et al. Trimethoprim: pharmacology, antimicrobial activity and clinical use in urinary tract infections. Ann Clin Res 1978;10, suppl 22:1-39.

${ }^{25}$ Fleming MP, Datta N, Grüneberg RN. Trimethoprim resistance determined by $\mathrm{R}$ factors. $\mathrm{Br}$ Med $\mathcal{F} 1972 ; \mathrm{i}: 726-8$.

${ }^{26}$ Jobanputrra RS, Datta N. Trimethoprim R factors in enterobacteria from clinical specimens. 7 Med Microbiol 1974;7:169-77.

27 Grüneberg RN, Bendall MJ. Hospital outbreak of trimethoprim resistance in pathogenic coliform bacteria. $\mathrm{Br} M e d \mathcal{F} 1979$;ii:7-9.

28 Threfall EJ, Ward LR, Ashley AS, Rowe B. Plasmid-encoded trimethoprim resistance in multiresistant epidemic Salmonella typhimurium phage types 204 and 193 in Britain. Br Med f 1980;280:1210-1.

\section{Oestrogen-replacement treatment in old age}

The endocrine aspects of aging ${ }^{1}$ are attracting much current interest; but perhaps the topic of greatest clinical concern is hormone replacement in postmenopausal women. The value of oestrogen treatment for some menopausal symptoms is undisputed, but what of continued oestrogen replacement into old age? What are the advantages and risks of such treatment for the elderly postmenopausal woman, and how justified is present enthusiasm, at least in the United Stateswhere a recent survey showed that $24 \%$ of women over 70 were receiving oestrogens. ${ }^{2}$

The main gain from treatment with oestrogens continued into old age is the prevention of osteoporosis. Osteoporosis and fractures are major problems in elderly women; onequarter of all white women have osteoporotic vertebral 
fractures by the age of 50, and the proportion rises to half by the age of $75 .^{3}$ Fractures are a major cause of both mortality and morbidity in old women. ${ }^{4}$

Oestrogen-replacement treatment certainly prevents loss of bone in the first decade after the menopause; this has been shown in both prospective studies ${ }^{5-8}$ and a careful retrospective case-control study. ${ }^{9}$ Such treatment is not, however, free from drawbacks. Firstly, its effectiveness is far greater if replacement is staried soon after the menopause. ${ }^{5} 9$ Secondly, when treatment is stopped loss of bone accelerates for a period so that treated patients may eventually be no better off than those who received no treatment at all. ${ }^{8}$ Furthermore, all the prospective studies have been short term (up to 10 years), and the benefits (in terms of reduced risk of osteoporosis and a lower incidence of fractures) have yet to be shown to be maintained into old age. The acceleration of bone loss after treatment is stopped implies that if oestrogen replacement is once started the patient is committed to continuing the treatment to the end of her life-on average some 30 years or so. We are asking for the patient's full compliance throughout this long period, for if each time treatment is stopped there is a period of increased bone loss erratic treatment might well do more harm than good in terms of skeletal mass.

The risks and inconveniences of treatment must, therefore, be very small if they are to be spread over such a prolonged period of time. The most publicised is endometrial hyperplasia, which carries an increased risk of endometrial carcinoma. ${ }^{1011}$ Endometrial hyperplasia may be substantially reduced by giving cyclical progestogens with the oestrogen, ${ }^{10}$ but the risks of even low-dose oestrogens in younger women are now well substantiated, and the progestogens given with low-dose oestrogens may be associated with increased risk of stroke and ischaemic heart disease. ${ }^{12}$ The dangers of oral contraceptive pills rise with age in premenopausal women, so that the risks of combined treatment with oestrogen and a progestogen after the menopause need to be assessed very carefully. An alternative approach is to use other anabolic steroids which do not stimulate the endometrium but do prevent loss of bone. ${ }^{13}$ Use of such an agent would remove the need for cyclical administration and thus for menstrual periods to continue throughout life-a price for prevention which many elderly women might find unacceptable.

The present evidence is still insufficient for a final decision whether treatment with oestrogen should be offered to all women from the time of the menopause for the rest of their lives in order to protect against osteoporosis and fracture in old age. ${ }^{14}$ Such treatment should not therefore be offered indiscriminately but studied carefully in further long-term clinical trials.

${ }^{1}$ Adlin EV, Korenman SG. Endocrine aspects of aging. Ann Intern Med 1980;92:429-31

2 Barrett-Connor E, Brown WV, Turner J, Austin M, Criqui MH. Heart disease risk factors and hormone use in postmenopausal women. fAMA $1979 ; \mathbf{2 4 1}: 2167-9$.

3 Greenblatt RB, Nezhat C, Roesel RA, Natrajan PK. Update on the male and female climacteric. F Am Geriatr Soc 1979;27:481-90.

t Gallannaugh SC, Martin A, Millard PH. Regional survey of femoral neck fractures. Br Med 7 1976;ii:1496-7.

5 Nachtigall LE, Nachtigall RH, Nachtigall RD, Beckman EM. Estrogen replacement therapy I: a 10-year prospective study in the relationship to osteoporosis. Obstet Gynecol 1979;53:277-81.

${ }^{6}$ Lindsay R, Hart DM, Aitken JM, MacDonald EB, Anderson JB, Clarke AC. Long-term prevention of postmenopausal osteoporosis by oestrogen. Lancet 1976; i:1038-40, 41.

; Meema S, Bunker ML, Meema HE. Preventive effect of estrogen on postmenopausal bone loss. A follow-up study. Arch Intern Med $1975 ; 135: 1436-40$.

- Lindsay R, MacLean A, Kraszewski A, Hart DM, Clark AC, Garwood J Bone response to termination of oestrogen treatment. Lancet 1978 ; 1325-7.
${ }^{9}$ Hutchinson TA, Polansky SM, Feinstein AR. Post-menopausal oestrogens protect against fractures of hip and distal radius. A case-control study. Lancet 1979 ;ii:705-9.

10 Thom MH, Studd JWW. Oestrogens and endometrial hyperplasia. Br F Hosp Med $1980 ; 23: 506-13$.

11 Hammond CB, Jelovsek FR, Lee KL, Creasman WT, Parker RT. Effects of long-term estrogen replacement therapy. II. Neoplasia. $A m \mathcal{f}$ Obstet Gynecol 1979;133:537-47.

12 Meade TW, Greenberg G, Thompson SG. Progestogens and cardiovascular reactions associated with oral contraceptives and a comparison of the safety of $50-$ and $30-\mu \mathrm{g}$ oestrogen preparations. $\mathrm{Br} \mathrm{Med} \mathcal{F}$ $1980 ; 280: 1157-61$.

${ }^{13}$ Lindsay R, Hart D McK, Kraszewski A. Prospective double-blind trial of synthetic steroid (Org OD 14) for preventing postmenopausal osteoporosis. $\mathrm{Br} \mathrm{Med} \mathcal{F} 1980 ; 280: 1207-9$.

14 Ryan KJ, Barrett-Connor E, Federman DD. Estrogen use and postmenopausal women: National-Institutes-of-Health Consensus Development Conference. Ann Intern Med 1979;91:921-2.

\section{How does smoking harm the heart?}

Cigarette smoking doubles the mortality from coronary heart disease, ${ }^{1-3}$ but the mechanism is unknown. This gap in knowledge may reflect our considerable uncertainty about the precise pathological processes underlying deaths attributed to coronary heart disease. ${ }^{4}$ Many such deaths, sudden and unheralded, are probably due to arrhythmias; these patients are found to have severe coronary atheroma but no thrombotic luminal occlusion. Though microembolism has been postulated, the precipitating cause of the terminal event is unknown. Transmural myocardial infarction, on the other hand, is associated with both severe coronary atheroma and thrombotic luminal occlusion. Death after the initial infarction may be due to pump failure or to arrhythmia. The increase in overall mortality from coronary heart disease produced by cigarette smoking could, therefore, be mediated by an unfavourable effect on atheroma, on thrombosis, or on the target organ itself by an alteration in the heart's susceptibility to arrhythmias or pump failure.

All of these mechanisms have been suggested as possible explanations. Increased coronary atheroma has been reported in smokers, ${ }^{5}$ while abnormalities have also been observed which in theory could produce an enhanced thrombotic tendency. These have ranged from changes in platelet survival ${ }^{6}$ and aggregation ${ }^{7}$ to raised plasma concentrations of fibrinogen and of coagulation factors. ${ }^{8}$ Finally, an increase in target-organ sensitivity has been reported in the form of the heart's ability to produce arrhythmias in response to catecholamines. ${ }^{9}$

These explanations have drawbacks, however. If, for example, smoking operates through a general effect on atheroma or thrombasis, why does it not act consistently on limb gangrene, cerebral infarction, and myocardial infarction? All are associated with severe atheroma of the supplying artery and with thrombotic luminal occlusion, but they show widely different patterns in their relation to cigarette consumption. ${ }^{10}$ Stroke, for example, is more closely linked with hypertension than with the other single risk factors such as hyperlipidaemia and smoking, which are powerful predictors for coronary heart disease. Even within the stroke group there is a differential association with cigarette smoking: in the Framingham study, men who smoked heavily had a threefold risk of developing a stroke, whereas in women no relation was found between smoking and the risk of stroke. ${ }^{11}$ Finally, if smoking increased the risk of vascular disease by enhancing thrombosis directly, rather than through an effect on atheroma, one would 